\title{
Left ventricular ejection fraction is associated with intraoperative circulatory collapse during transcatheter aortic valve implantation
}

\author{
Bo Fu ${ }^{1,2 \#}$, Shaopeng Zhang ${ }^{2 \#}$, Shilin Dai ${ }^{1 \#}$, Zhigang Guo ${ }^{2}$, Nan Jiang ${ }^{2}$, Jiange Han ${ }^{3}$, Li Yang ${ }^{4}$, \\ Yanwen Shang ${ }^{5}$, Yanhe Ma ${ }^{6}$, Thomas Puehler ${ }^{7}$, Rodrigo Bagur ${ }^{8}$ \\ ${ }^{1}$ Tianjin Medical University, Tianjin, China; ${ }^{2}$ Department of Cardiovascular Surgery, Tianjin Chest Hospital, Tianjin, China; ${ }^{3}$ Department of \\ Anesthesiology, Tianjin Chest Hospital, Tianjin, China; ${ }^{4}$ Department of Cardiology, Tianjin Chest Hospital, Tianjin, China; ${ }^{5}$ Department of \\ Echocardiography, Tianjin Chest Hospital, Tianjin, China; ${ }^{6}$ Department of Radiology, Tianjin Chest Hospital, Tianjin, China; ${ }^{7}$ Department of \\ Cardiovascular Surgery, University Hospital Schleswig-Holstein, Kiel, Germany; ${ }^{8}$ University Hospital, London Health Sciences Centre, London, \\ ON, Canada \\ Contributions: (I) Conception and design: B Fu, N Jiang; (II) Administrative support: Z Guo; (III) Provision of study materials or patients: B Fu, \\ S Zhang, S Dai, J Han; (IV) Collection and assembly of data: N Jiang; (V) Data analysis and interpretation: B Fu, L Yang, Y Shang, Y Ma; (VI) \\ Manuscript writing: All authors; (VII) Final approval of manuscript: All authors. \\ "These authors contributed equally to this work. \\ Correspondence to: Prof. Nan Jiang, MD; Prof. Zhigang Guo, MD. Department of Cardiovascular Surgery, Tianjin Chest Hospital, No. 261, South \\ Taierzhuang Road, Tianjin, China. Email: tjxkcs2@163.com; zhigangguo@yahoo.com.
}

Background: Intraoperative hemodynamic collapse during transcatheter aortic valve implantation (TAVI) is a devastating complication that requires mechanical support. In this study, we sought to analyze our early experience in using cardiopulmonary bypass (CPB) support to circumvent circulatory compromise during TAVI.

Methods: Between January 2018 and December 2020, 102 consecutive patients (54 males; mean age, $71.2 \pm 8.9$ years) received TAVI at Tianjin Chest Hospital, and an emergency CPB device was used in 6 of these patients $(5.9 \%)$. The clinical data of the CPB and no-CPB groups were analyzed to identify the factors associated with intraoperative hemodynamic collapse requiring CPB.

Results: All 6 patients who needed emergency CPB support were successfully weaned from the device. This group had a higher Society of Thoracic Surgeons Score [4.09 (2.02, 6.85) vs. 7.47 (5.07, 23.46); $\mathrm{P}=0.030]$, more patients with a left ventricular ejection fraction (LVEF) $\leq 30 \%$ [4 (66.7\%) vs. 2 (2.1\%); $\mathrm{P}=0.000]$, a larger right ventricle anteroposterior diameter $[20.50$ (19.75, 21.25) vs.19.00 (17.00, 20.00); $\mathrm{P}=0.016]$, and a higher degree of aortic regurgitation $[4.50$ (2.75, 5.00) vs. 2.00 (1.00, 4.00); $\mathrm{P}=0.018]$ compared to the no-CPB group. The CPB group also had a higher in-hospital mortality rate than did the no-CPB group (16.7\% vs. 4.7\%; $\mathrm{P}=0.026$ ). Multivariable analysis determined that the presence of lower preTAVI LVEF was associated with intraoperative hemodynamic collapse.

Conclusions: Our results indicate that LVEF is an independent risk factor for requiring emergency CPB during the TAVI procedure. The need for emergency CPB support was associated with higher in-hospital mortality.

Keywords: Extracorporeal assisted cardiopulmonary resuscitation (ECPR); cardiopulmonary bypass (CPB); transcatheter aortic valve implantation (TAVI); left ventricular ejection fraction (LVEF); hemodynamic collapse

Submitted May 08, 2021. Accepted for publication Aug 05, 2021.

doi: 10.21037/atm-21-3446

View this article at: https://dx.doi.org/10.21037/atm-21-3446 


\section{Introduction}

Since first being introduced by Cribier in 2002 (1), transcatheter aortic valve implantation (TAVI) has revolutionized the surgical treatment of aortic stenosis (AS). Most candidates for TAVI procedures are elderly patients who have high perioperative risks. These patients can easily deteriorate into a state of circulatory collapse, which is a devastating complication reported in $4-15.2 \%$ of these patients (2-5). Pulmonary hypertension, biventricular failure, transapical access, and cardiogenic shock due to hemodynamic collapse necessitating salvage mechanical support have all been reported in patients undergoing TAVI $(6,7)$.

The emergency use of mechanical circulatory support (MCS) is technically feasible, safe, and effective, and guarantees adequate hemodynamic stability during TAVI $(5,8-10)$. However, the available data have thus far failed to provide clear-cut guidelines regarding the indications for MCS, leaving the decision regarding its application to the consensus of the heart team $(11,12)$. Unfortunately, experience on the use of emergency MCS in averting or correcting intraoperative circulatory collapse is quite limited (4). Therefore, there is a great need and interest for a detailed discussion on the salvage use of MCS. The current study aimed to analyze the emergency use of cardiopulmonary bypass (CPB) support during TAVI and to assess the related risk factors for intraoperative circulatory collapse during TAVI in a Chinese population. We present the following article in accordance with the STROBE reporting checklist (available at https:// dx.doi.org/10.21037/atm-21-3446).

\section{Methods}

\section{Participants}

Clinical data of 102 consecutive patients who underwent the TAVI procedure in Tianjin Chest Hospital, China, between January 2018 and December 2020 were retrospectively collected. All procedures were completed using selfexpanding transcatheter bioprostheses. Transfemoral TAVI was carried out in 90 patients (Figure 1), and the other 12 patients underwent transapical TAVI. Six patients required emergency $\mathrm{CPB}$ support for refractory circulatory collapse. All procedures in this study involving human participants were performed in accordance with the Declaration of Helsinki (as revised in 2013). This study was approved by the institutional review board of Tianjin Chest Hospital [approval no. IRB-SOP-016(F)-001-02]. Informed consent was taken from all the patients.

\section{Participant election criteria}

All patients who were scheduled to undergo a TAVI procedure at our hospital and consented to participate were
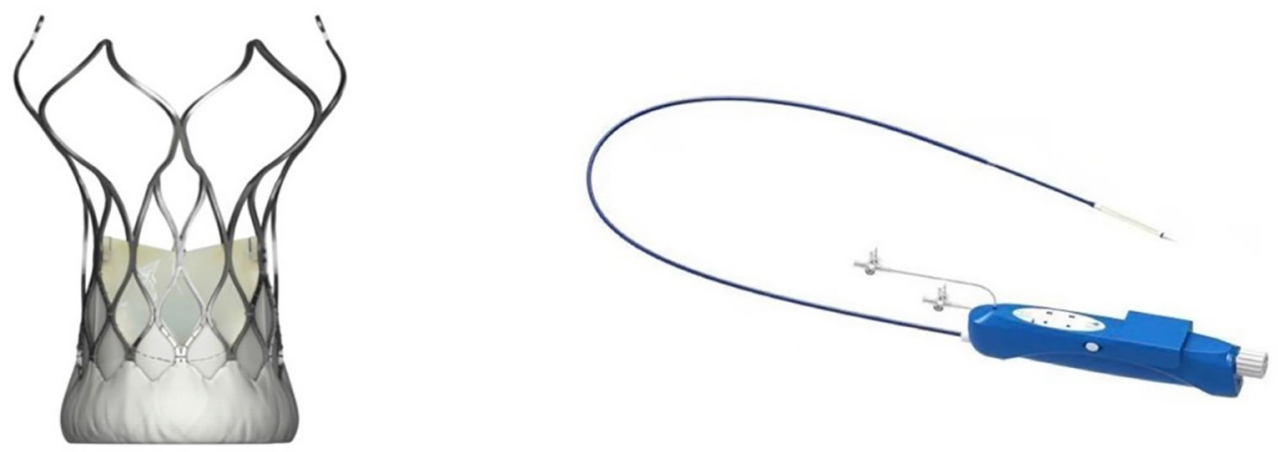

Figure 1 Product features of the VitaFlow Transcatheter Aortic Valve System. VitaFlow Transcatheter Aortic Valve System (VitaFlow) is a transfemoral (TF) valve made of trileaflet bovine pericardium in China. The system comprises a valve and a delivery system. VitaFlow uses bovine pericardium with patented anticalcification treatment as the leaflet material, which provides better durability. The "supra-annular" design preserves circularity and provides a large effective orifice area and low gradients. The frame of the VitaFlow valve has a hybrid density design, which delivers a balance of high radial force, space for the possible subsequent percutaneous coronary intervention, and the flexibility of the whole system. Additionally, the VitaFlow valve has an inner and outer polyethylene terephthalate skirt design, which can better fit the aortic root structure and reduce the paravalvular leakage. The motorized handle of the VitaFlow delivery system is easy to use, providing precise and stable positioning. There is also a manual, backup handle. The profile of the delivery system is $16 \mathrm{~F}$ or $18 \mathrm{~F}$. 

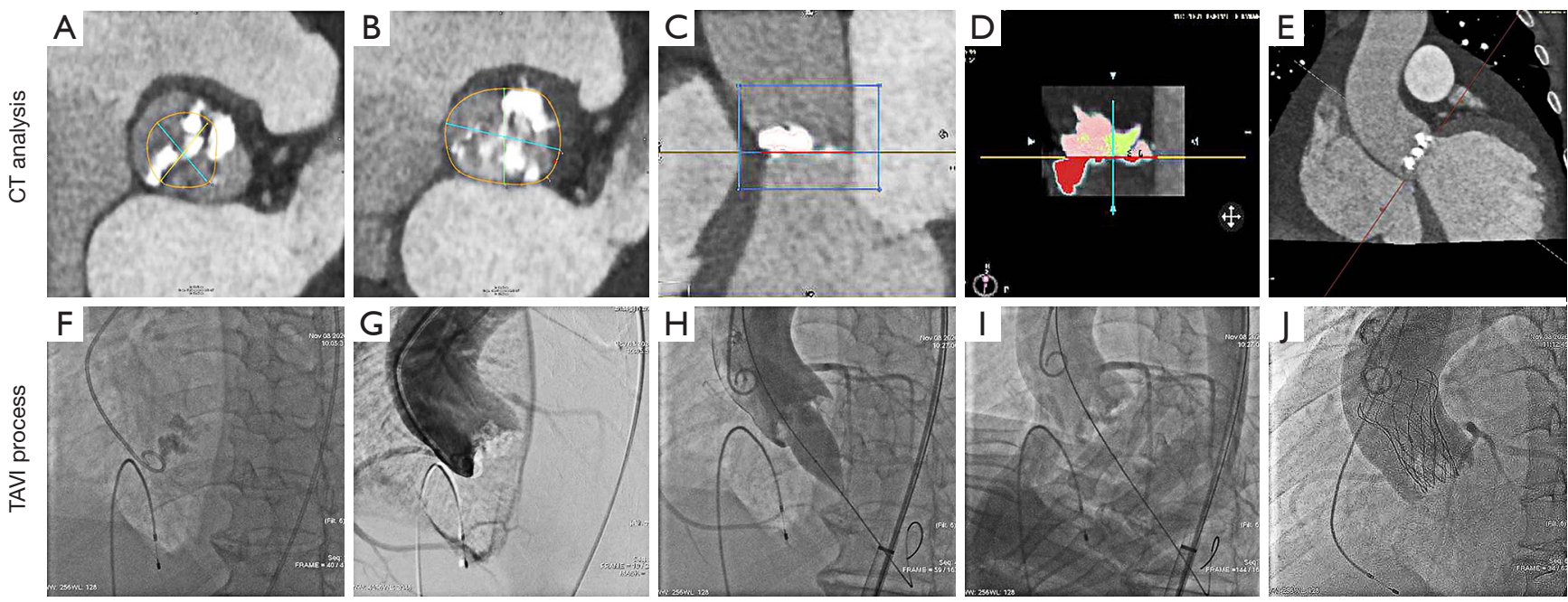

Figure 2 Cardiopulmonary bypass support to circumvent circulatory compromise during the transcatheter aortic valve implantation (TAVI) procedure. A 49-year-old male, whom surgeons considered not to be a suitable candidate for surgery, underwent TAVI with emergency intraoperative cardiopulmonary bypass (CPB) support. He presented with orthopnea and massive pleural effusion. Transthoracic echocardiography indicated severely calcified bicuspid aortic valve stenosis, moderate aortic regurgitation, and moderate to severe mitral regurgitation with a pulmonary arterial systolic pressure of $50 \mathrm{mmHg}$. Transesophageal echocardiography showed a mean aortic valve gradient of $55 \mathrm{mmHg}$, a maximum transaortic velocity of $4.5 \mathrm{~m} / \mathrm{s}$, and a left ventricular ejection fraction of $28 \%$. The patient suffered from a hemodynamic collapse as a result of ventricular fibrillation after balloon predilation. The images show the patient's aortic root measurement and the entire TAVI procedure. (A) Supra-annular narrowing of the bicuspid valve at $6 \mathrm{~mm}$ above the basal ring. (B) The level of the basal ring: the minimum diameter was $28.62 \mathrm{~mm}$, the max diameter was $37.82 \mathrm{~mm}$, and the area was $9.11 \mathrm{~cm}^{2}$. (C) Calcium volume of calcification volume (calcification detection was set at 850 Hounsfield units): the aortic valve region calcium was $1,116.0 \mathrm{~mm}^{3}$. (D) The first bicuspid cusp was $797.5 \mathrm{~mm}^{2}$, and the second bicuspid cusp was $318.4 \mathrm{~mm}^{2}$. (E) Aortic angulation. (F) The pigtail catheter located at the base of the coronary sinus. $(\mathrm{G})$ Aortic root angiography. $(\mathrm{H})$ Recalcitrant ventricular fibrillation occurred after aortic predilation with a 20-mm balloon. (I) Cardiopulmonary resuscitation and femoral arteriovenous intubation were initiated immediately. The valve release assisted by CPB proceeded as follows: suspension of extracorporeal assistance, exsanguination, release, restart of $\mathrm{CPB}$, and defibrillation. The prosthetic valve localization was indicated by calcified plaques of the native valve. (J) Both coronaries were patent, and no perivalvular leak was detected. The patient was weaned from CPB after 61 minutes of support. After the procedure, transesophageal echocardiography indicated that the mean transvalvular gradient was $10 \mathrm{mmHg}$, the maximum transaortic velocity was $2 \mathrm{~m} / \mathrm{s}$, and the effective orifice area was $1.9 \mathrm{~cm}^{2}$. (Self-expandable valve: \#24 VitaFlow, MicroPort, Shanghai, China).

eligible for inclusion in the study. Patients who died or who were converted to open surgery with complications, patients with incomplete clinical data, and patients who did not consent to participate in the study were excluded from the analysis.

\section{Perioperative management}

All patients received transthoracic echocardiography, and multislice computed tomography (MSCT) measurements were used to assess the anatomy of the aortic root and select the surgical approach, in line with the current guidelines (2). Curved multiplanar reconstruction analyses were used for annular and aortic valve dimension descriptions (software: CVI 42, version 5.12.1 Circle Cardiovascular Imaging, Calgary, AB, Canada; Figure 2). The multidisciplinary surgical team held a routine preoperative discussion with each patient to identify, avert, and plan for the handling of any potential complications. Procedures were monitored with transesophageal echocardiography, fluoroscopy, and angiography. Doppler examination was performed to evaluate the severity of paravalvular leakage, and valve regurgitation was classified as none/trace, mild, moderate, or severe, as previously described (2).

A hybrid operating suite with standby CPB was used for all TAVI procedures. The routine TAVI operative 
procedure and management strategy adopted were described in our previous study (13). After administration of general anesthesia, we performed a routine puncture of the femoral artery and vein. In general, for patients whose complicated circulatory compromise occurred before the valve intervention could be performed, cardiopulmonary resuscitation, external defibrillation, and adjustment of medication were applied. If cardiopulmonary resuscitation proved unsuccessful after 2 rounds, then cannulation was performed. In the event of circulatory failure occurring during valve release, the first option was to release the valve and then perform cardiopulmonary resuscitation.

\section{Statistical evaluation}

Data were tested for normality distribution with the Kolmogorov-Smirnov (K-S) test. Normally distributed data are presented as means \pm standard deviations and were compared using the independent-samples $t$ test. Data that did not show a normal distribution were summarized as means and interquartile ranges, and comparisons were conducted using the Mann-Whitney $U$ test. Categorical data are presented as frequencies and percentages, and comparisons were made using the $\chi^{2}$ or Fisher's exact test. Variables displaying a $\mathrm{P}<0.2$ were included in a logistic regression model for multivariate analysis. Two-tailed tests were used, with a $\mathrm{P}$ value $<0.05$ being considered statistically significant. The SPSS version 22.0 software (IBM Corp., Armonk, NY, USA) was used for statistical analysis.

\section{Results}

\section{Baseline characteristics}

Intraoperative circulatory collapse occurred in 13 patients: CPB was used in 6 of these cases (46.2\%), and cardiopulmonary resuscitation proved successful in 7 of these cases.

As shown in Table 1, demographic characteristics, including age, sex, and body mass index, were similar between patients who underwent CPB and those who did not. Both groups were similar in terms of comorbidities including hypertension, chronic obstructive pulmonary disease (COPD), diabetes, coronary artery disease, previous myocardial infarction, previous percutaneous coronary intervention (PCI), previous coronary artery bypass grafting (CABG), and bicuspid aortic valves. Atrial fibrillation was more prevalent in the $\mathrm{CPB}$ group. Notably, more patients in the CPB group underwent transapical TAVI than did those in the no-CPB group (50\% vs. 9.4\%; $\mathrm{P}=0.018)$.

\section{Echocardiographic data}

The echocardiographic data showed that the CPB group had a larger right ventricle diameter $[20.50(19.75,21.25$ vs. $19.00(17.00,20.00) \mathrm{mm} ; \mathrm{P}=0.016]$, higher pulmonary artery systolic pressure $[47.50(41.25,65.25)$ vs. 35.00 (30.00, 41.00) $\mathrm{mmHg} ; \mathrm{P}=0.017)$, a larger proportion of patients with LVEF $\leq 30 \%$ [4 (66.7\%) vs. 2 (2.1\%); $\mathrm{P}<0.001$ ], and more moderate to severe aortic regurgitation $[4.50$ (2.75, 5.00) vs. 2.00 (1.00, 4.00); $\mathrm{P}=0.018$ ] than did the no-CPB group. The left ventricular end-diastolic dimension in the $\mathrm{CPB}$ group was larger than that in the no-CPB group, but this discrepancy was not significantly significant [66.00 (60.50, 67.75) vs. 57.00 (50.00, 66.00); $\mathrm{P}=0.101]$. The 2 groups were comparable regarding the maximum transaortic velocity, mean pressure gradient, aortic valve area, and degree of mitral regurgitation.

\section{Reasons for using $C P B$}

The characteristics of the patients that underwent emergency use of CPB are detailed in Table 2. Of these 6 cases, 3 patients collapsed after predilation [1 patient experienced a sudden drop in systolic blood pressure, while 2 cases had ventricular fibrillation (VF)], 2 patients experienced VF during valve release, and 1 patient experienced a sudden drop in systolic blood pressure after the passage of the guidewire through the native aortic valve. The mean duration of the $\mathrm{CPB}$ procedure was 68 minutes (range, 31124 minutes) and all patients were successfully weaned from the CPB device after a short duration of support.

\section{Outcomes and survival}

Four $(16.7 \%)$ in-hospital deaths occurred in the no-CPB group, compared with one (4.7\%) such death in the CPB group $(\mathrm{P}=0.026)$. The length of stay in the intensive care unit $(\mathrm{P}=0.036)$ and overall length of hospital stay $(\mathrm{P}=0.026)$ in the $\mathrm{CPB}$ group were higher than those in the no- $\mathrm{CPB}$ group. There was no significant difference in the frequency of new pacemaker insertion ( $10.6 \%$ vs. $16.7 \% ; \mathrm{P}=0.359)$, mean postprocedural gradient (8.00 vs. $10.00 \mathrm{mmHg}$; $\mathrm{P}=0.189$ ), or incidence of peripheral arterial complications (3.1\% vs. 16.7\%; $\mathrm{P}=0.139$ ) between the 2 groups (Table 3).

In the multivariate model, the presence of LVEF $\leq 30 \%$ was identified as an independent factor associated with the 
Table 1 Baseline characteristics of patients who underwent TAVI with or without CPB support

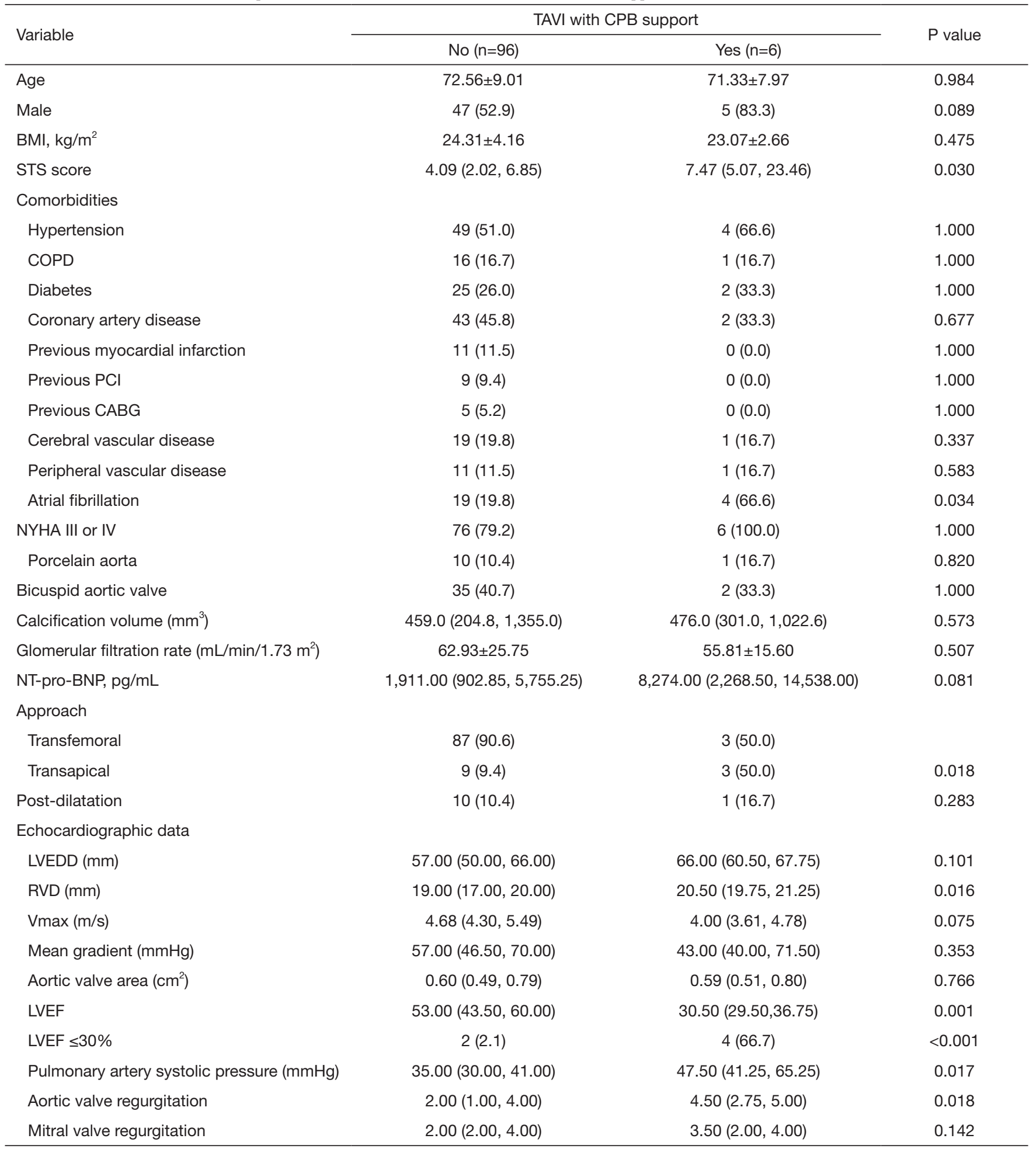

Values presented as mean $\pm \mathrm{SD}, \mathrm{n}(\%)$, or median (IQR). TAVI, transcatheter aortic valve implantation; CPB, cardiopulmonary bypass; STS, Society of Thoracic Surgeons; COPD, chronic obstructive pulmonary disease; PCI, previous percutaneous transluminal coronary intervention; CABG, previous coronary artery bypass grafting; NYHA, New York Heart Association; NT-pro-BNP, N-terminal pro brain natriuretic peptide; Vmax (m/s), maximum aortic valve gradient; LVEDD, left ventricular-diastolic diameter; RVD, right ventricular diameter; LVEF\%, percentage of left ventricular ejection fraction. 
Table 2 Characteristics of patients who received emergency CPB support during TAVI

\begin{tabular}{lccccccc}
\hline Patients & Age & Sex & STS score & LVEF $(\%)$ & Approach & Reason for CPB & CPB duration (min) \\
\hline 1 & 81 & M & 36.45 & 30 & Transapical & Sudden systolic blood pressure drop after predilation & \\
2 & 72 & M & 2.68 & 29 & Transfemoral & Blood pressure drop after passage of the guidewire & 31 \\
3 & 73 & M & 5.86 & 30 & Transapical & VF after aortic balloon valvuloplasty (predilation) & 37 \\
4 & 75 & M & 6.43 & 42 & Transapical & Refractory VF during the process of releasing & 115 \\
5 & 70 & F & 8.51 & 35 & Transfemoral & Refractory VF during the process of releasing & 40 \\
6 & 57 & M & 19.11 & 28 & Transfemoral & VF after aortic balloon valvuloplasty (predilation) &
\end{tabular}

CPB, cardiopulmonary bypass; TAVI, transcatheter aortic valve implantation; LVEF\%, percentage of left ventricular ejection fraction; VF, ventricular fibrillation.

Table 3 Outcomes of patients who underwent TAVI with or without CPB support

\begin{tabular}{lccc}
\hline & Without CPB support & CPB support & P value \\
\hline In-hospital mortality & $4(4.7)$ & $1(16.7)$ & 0.026 \\
Length of ICU stay (d) & $2.00(2.00,3.00)$ & $3.50(2.00,8.00)$ & 0.036 \\
Length of hospital stay (d) & $7.00(6.50,9.00)$ & $11.00(8.00,12.50)$ & 0.026 \\
Cost of hospitalization (RMB) & $326.40(276.40,343.90)$ & $360.20(320.05,404.05)$ & 0.089 \\
New pacemaker & $2(2.08)$ & $1(16.7)$ & 0.109 \\
Mean postoperative gradient $(\mathrm{mmHg})$ & $8.00(5.00,13.00)$ & $10.00(8.50,12.00)$ & 0.189 \\
Peripheral arterial complication & $3(3.1)$ & $1(16.7)$ & 0.139 \\
\hline
\end{tabular}

Values presented as $\mathrm{n}(\%)$ or median (IQR). TAVI, transcatheter aortic valve implantation; CPB, cardiopulmonary bypass; ICU, intensive care unit.

Table 4 Results of multivariate analysis

\begin{tabular}{lccc}
\hline & Regression coefficient & P value & OR (95\% Cl) \\
\hline Approach & -5.290 & 0.050 & $0.000-0.992$ \\
LVEF $\leq 30 \%$ & -7.889 & 0.017 & $0.000-0.240$ \\
LVEDD $(\mathrm{mm})$ & -0.169 & 0.136 & $0.676-1.055$ \\
RVD $(\mathrm{mm})$ & -0.680 & 0.054 & $1.020-3.818$ \\
\hline
\end{tabular}

OR, odds ratio; 95\% CI, 95\% confidence interval; LVEDD, left ventricular-diastolic diameter, LVEF, left ventricular ejection fraction; RVD, right ventricular diameter.

need for emergency $\mathrm{CPB}$ during TAVI $[\mathrm{P}=0.017$; odds ratio (OR) :0.000-0.240; Table 4].

\section{Discussion}

There has been a drastic increase in the number of TAVI procedures in China since the first successful operation was reported in 2010. As attested to by the 2020 White
Paper of China Structural Heart Disease (12), more than 6,000 operations have been successfully carried out across China using the technique. Over the past year alone, more than 3,500 TAVI procedures have been performed at more than 200 centers. Further, in addition to the Edwards SAPIEN valve (Edwards Lifesciences, Irvine, CA, USA), a balloon-expandable valve that is frequently used in Western countries (4), becoming the most popular device approved 
by the National Medical Products Administration, three other domestically produced self-expandable prostheses (the VitaFlow Valve, J-Valve, and Venus A-valve) have played a central role in the expansion of TAVI in China. However, due to the severe calcification associated with the bicuspid valve, Chinese doctors still prefer and frequently use firstgeneration nonrecoverable TAVI valves. The collective experience of Chinese surgeons in the use of diverse valvular devices is still nascent and limited. Therefore, determining the clinical indications, implantation strategies, intraoperative emergency management, and valve durability for TAVI still requires further clarification. Our study highlights the fact that emergency CPB is still required and is needed at a higher frequency than that reported in previous studies. The previous study indicated low LVEF has been strongly associated with circulatory collapse requiring CPB support during TAVI $(14,15)$. It is possible that patients with depressed LVEF have a severely compromised decompensation capacity, resulting in a poor tolerance to predilation balloon valvuloplasty and inherent rapid ventricular pacing.

Unbehaun et al. (16) and Schaefer et al. (10) found that patients with a very poor LVEF and an enlarged right ventricle were more likely to develop hemodynamic collapse, which was also observed in the present study. Other researchers have also reported that pulmonary hypertension, biventricular failure, transapical access, and cardiogenic shock are independent risk factors for requiring CPB during TAVI (4,6-8). However, our results indicated that influence of LVEF accounted for less than 30\% among the factors associated with the need for CPB.

The management of patients with AS, especially those diagnosed as stage D2 and D3, is quite challenging $(14,17)$. Approximately 1 in 3 of these patients die within 2 years (18). Drews et al. (8) reported that the prophylactic use of CPB may increase the safety of the TAVI procedure for patients who have severely reduced heart function. These researchers recommended that valvuloplasty and valve deployment be considered for short-term CPB support in patients with poor LVEF (10-20\%) or decompensated right ventricular failure. Another retrospective study (5) found that the emergency use of MCS during TAVI in extremely high-risk groups of patients was associated with high mortality rates (30-46\%). Taken together, the available data suggest that the primary use of $\mathrm{CPB}$, rather than its secondary, emergency use, may provide superior results. There is, however, the possibility of selection bias in the sampled studies. Currently, evidence on the prophylactic use of MCS in critically ill patients undergoing TAVI procedures is limited. Moreover, the specific indications and optimal treatment for emergency implantation of CPB devices are usually determined by heart team consensus (11).

Additional indications for MCS noted in other studies include left ventricular or aortic annular rupture, aortic dissection, severe aortic regurgitation or paravalvular leak, and coronary occlusion $(4,5,19)$. These life-threatening complications often lead to hemodynamic collapse, which requires expeditious use of $\mathrm{CPB}$ support to avert a disastrous outcome (20).

It is worth noting that not all forms of hemodynamic collapse require mechanical support. In our study, in addition to the $6 \mathrm{CPB}$ recipients, 7 patients $(53.8 \%, 7 / 13)$ who experienced circulatory collapse did not receive $\mathrm{CPB}$ support but recovered after receiving the comprehensive management mentioned above. Among them, 3 patients developed VF and a drop in blood pressure during or after rapid pacing for balloon predilation. During valve deployment, 1 and 2 patients suffered from VF and hypotension, respectively. While performing intraoperative CPB implantation during the management of circulatory collapse, we considered the following: (I) Refractory hypotension or persistent hemodynamic frequent occurred after high-dose vasopressor treatment before the operation. (II) During the valve deployment step, we first chose to release the valve without rapid pacing and then attempted cardiopulmonary resuscitation. (III) During the period before interposition of the valve device, a comprehensive rescue strategy was initiated via cardiopulmonary resuscitation, external defibrillation, and medication adjustment. The initial cannulation would only be started after 2 rounds of cardiopulmonary resuscitation had failed. (IV) In the event of circulatory collapse due to aortic root or left ventricular rupture, pericardial tamponade, or aortic dissection, $\mathrm{CPB}$ was immediately initiated. Particular attention should be paid to patients at high risk of rupture, especially those with an oversized valve, a heavily calcified annulus, or an annulus with an enhanced oval shape $(21,22)$.

The choice of MCS device in the procedures was individualized not only based on the conditions of the patient, but also related to clinical setting, such as the urgency of the required support, the operator's experience, and hospital availability. Among patients with preoperative severe heart failure who needed long-term hemodynamic assistance after surgery, venous-arterial extracorporeal membrane oxygenation (VA-ECMO) was used. ECMO has the benefit of having fairly high availability and is thus 
used in many centers. However, 1 study recorded a low success rate $(56.5 \%)$ with ECMO, with $45.5 \%$ of cases requiring upgrading to $\mathrm{CPB}$ for open conversion (23). We used $\mathrm{CPB}$, a well-established technique in our center, to manage all cases of refractory circulatory compromise, with a device success rate of $100 \%$. Other studies have also used CPB for MCS (20), reporting mortality rates (9.6\%) and complications (59.4\%) comparable with those of ECMO $(6,20,24)$. We acknowledge that there are limitations to the current study. First, our research has the associated weakness of all retrospective studies. Data were limited regarding the $\mathrm{CPB}$ group, as the procedure was only rarely applied. Second, the findings might have been affected by those TAVI procedures performed in the early experience of center. Nonetheless, our approach will inevitably improve through extensive practical training and accumulated local clinical experience.

\section{Conclusions}

LVEF was found to be an independent risk factor for emergency CPB implantation during the TAVI procedure. The need for emergency CPB support was associated with higher in-hospital mortality.

\section{Acknowledgments}

The authors appreciate the academic support from the AME Cardiovascular Surgery Collaborative Group.

Funding: This research was supported by funding from The National Key Research and Development Program of China (no. 2020YFC2008100).

\section{Footnote}

Reporting Checklist: The authors have completed the STROBE reporting checklist. Available at https://dx.doi. org/10.21037/atm-21-3446

Data Sharing Statement: Available at https://dx.doi. org/10.21037/atm-21-3446

Conflicts of Interest: All authors have completed the ICMJE uniform disclosure form (available at https://dx.doi. org/10.21037/atm-21-3446). The authors have no conflicts of interest to declare.

Ethical Statement: The authors are accountable for all aspects of the work in ensuring that questions related to the accuracy or integrity of any part of the work are appropriately investigated and resolved. All procedures performed in this study involving human participants were in accordance with the Declaration of Helsinki (as revised in 2013). The study was approved by institutional review board of Tianjin Chest Hospital [no. IRB-SOP016(F)-001-02] and informed consent was obtained from all the patients.

Open Access Statement: This is an Open Access article distributed in accordance with the Creative Commons Attribution-NonCommercial-NoDerivs 4.0 International License (CC BY-NC-ND 4.0), which permits the noncommercial replication and distribution of the article with the strict proviso that no changes or edits are made and the original work is properly cited (including links to both the formal publication through the relevant DOI and the license). See: https://creativecommons.org/licenses/by-nc-nd/4.0/.

\section{References}

1. Cribier A, Eltchaninoff H, Bash A, et al. Percutaneous transcatheter implantation of an aortic valve prosthesis for calcific aortic stenosis: first human case description. Circulation 2002;106:3006-8.

2. Otto CM, Nishimura RA, Bonow RO, et al. 2020 ACC/ AHA Guideline for the Management of Patients With Valvular Heart Disease: A Report of the American College of Cardiology/American Heart Association Joint Committee on Clinical Practice Guidelines. Circulation 2021;143:e72-227. Erratum in: Circulation 2021;143:e229.

3. Banjac I, Petrovic M, Akay MH, et al. Extracorporeal Membrane Oxygenation as a Procedural Rescue Strategy for Transcatheter Aortic Valve Replacement Cardiac Complications. ASAIO J 2016;62:e1-4.

4. Vallabhajosyula S, Patlolla SH, Sandhyavenu H, et al. Periprocedural Cardiopulmonary Bypass or Venoarterial Extracorporeal Membrane Oxygenation During Transcatheter Aortic Valve Replacement: A Systematic Review. J Am Heart Assoc 2018;7:009608.

5. Roselli EE, Idrees J, Mick S, et al. Emergency use of cardiopulmonary bypass in complicated transcatheter aortic valve replacement: importance of a heart team approach. J Thorac Cardiovasc Surg 2014;148:1413-6.

6. Singh V, Patel SV, Savani C, et al. Mechanical circulatory support devices and transcatheter aortic valve implantation (from the National Inpatient Sample). Am J Cardiol 
2015;116:1574-80.

7. Trenkwalder T, Pellegrini C, Holzamer A, et al. Prophylactic ECMO during TAVI in patients with depressed left ventricular ejection fraction. Clin Res Cardiol 2019;108:366-74.

8. Drews T, Pasic M, Buz S, et al. Elective use of femorofemoral cardiopulmonary bypass during transcatheter aortic valve implantation. Eur J Cardiothorac Surg 2015;47:24-30; discussion 30.

9. Drews T, Pasic M, Buz S, et al. Elective femoro-femoral cardiopulmonary bypass during transcatheter aortic valve implantation: a useful tool. J Thorac Cardiovasc Surg 2013;145:757-63.

10. Schaefer U, Zahn R, Abdel-Wahab M, et al. Comparison of outcomes of patients with left ventricular ejection fractions $\leq 30 \%$ versus $\geq 30 \%$ having transcatheter aortic valve implantation (from the German Transcatheter Aortic Valve Interventions Registry). Am J Cardiol 2015;115:656-63.

11. Giri JS, Szerlip M, Devireddy C, et al. SCAI 2018 Think Tank Proceedings: "What should the role of the surgeon be in TAVR, both as a co-operator and inpatient evaluation for TAVR? Catheter Cardiovasc Interv 2019;93:178-9.

12. Structural Cardiology Committee of Chinese Medical Doctor Association. China Structural Heart Disease Annual Report 2020.

13. Fu B, Chen Q, Zhao F, et al. Efficacy and safety of transcatheter aortic valve implantation in patients with severe bicuspid aortic stenosis. Ann Transl Med 2020;8:873.

14. Pibarot P, Dumesnil JG. Low-flow, low-gradient aortic stenosis with normal and depressed left ventricular ejection fraction. J Am Coll Cardiol 2012;60:1845-53.

15. Eleid MF, Michelena HI, Nkomo VT, et al. Causes of death and predictors of survival after aortic valve replacement in low flow vs. normal flow severe aortic stenosis with preserved ejection fraction. Eur Heart J

Cite this article as: Fu B, Zhang S, Dai S, Guo Z, Jiang N, Han J, Yang L, Shang Y, Ma Y, Puehler T, Bagur R. Left ventricular ejection fraction is associated with intraoperative circulatory collapse during transcatheter aortic valve implantation. Ann Transl Med 2021;9(16):1336. doi: 10.21037/ atm-21-3446
Cardiovasc Imaging 2015;16:1270-5.

16. Unbehaun A, Pasic M, Buz S, et al. Transapical aortic valve implantation in patients with poor left ventricular function and cardiogenic shock. J Thorac Cardiovasc Surg 2014;148:2877-82.e1.

17. Baumgartner H, Falk V, Bax JJ, et al. 2017 ESC/EACTS Guidelines for the management of valvular heart disease. Eur Heart J 2017;38:2739-91.

18. Ribeiro HB, Lerakis S, Gilard M, et al. Transcatheter Aortic Valve Replacement in Patients With Low-Flow, Low-Gradient Aortic Stenosis: The TOPAS-TAVI Registry. J Am Coll Cardiol 2018;71:1297-308.

19. Raffa GM, Kowalewski M, Meani P, et al. In-hospital outcomes after emergency or prophylactic venoarterial extracorporeal membrane oxygenation during transcatheter aortic valve implantation: a comprehensive review of the literature. Perfusion 2019;34:354-63.

20. Singh V, Damluji AA, Mendirichaga R, et al. Elective or Emergency Use of Mechanical Circulatory Support Devices During Transcatheter Aortic Valve Replacement. J Interv Cardiol 2016;29:513-22.

21. Wang Q, Kodali S, Primiano C, et al. Simulations of transcatheter aortic valve implantation: implications for aortic root rupture. Biomech Model Mechanobiol 2015;14:29-38.

22. Fernandes P, Cleland A, Bainbridge D, et al. Development of our TAVI protocol for emergency initiation of cardiopulmonary bypass. Perfusion 2015;30:34-9.

23. Trenkwalder T, Pellegrini C, Holzamer A, et al. Emergency extracorporeal membrane oxygenation in transcatheter aortic valve implantation: A twocenter experience of incidence, outcome and temporal trends from 2010 to 2015. Catheter Cardiovasc Interv 2018;92:149-56.

24. Ajam F, Patel S, Asgarian K, et al. Cannulation of the Femoral Arterial Bypass Cannula Allows Completion of TAVR in Unstable Patients. Ann Thorac Surg 2019;107:e297-9. 